\title{
(2) OPEN ACCESS \\ Successful peripheral nerve block under dexmedetomidine sedation for femoral neck fracture fixation in a 97-year-old patient
}

\author{
Yoshiaki Ishida ำ, Fumiko Ogura, Satoko Kondo, Yoshie Toba
}

Anesthesiology, Seirei Hamamatsu Hospital, Hamamatsu, Shizuoka, Japan

\section{Correspondence to} Dr Yoshiaki Ishida; cogito_ergo_sum_yoshiaki@ yahoo.co.jp

Accepted 19 March 2021

Check for updates

(c) BMJ Publishing Group Limited 2021. Re-use permitted under CC BY-NC. No commercial re-use. See rights and permissions. Published by BMJ.

To cite: Ishida $Y$, Ogura $F$, Kondo $\mathrm{S}$, et al. BMJ Case Rep 2021:14:e239468. doi:10.1136/bcr-2020239468

\section{SUMMARY}

Hip fracture is a common injury in elderly patients. In Japan, the number of super-old patients - age $>90$ years - with hip fractures has increased drastically over time. Available strategies for anaesthetic management for hip fracture surgery include general anaesthesia, neuraxial anaesthesia and peripheral nerve block. However, general and neuraxial anaesthesia are often avoided for various reasons, particularly in elderly patients. In recent years, peripheral nerve block has proven effective in various surgical procedures. Additionally, dexmedetomidine exhibits neuroprotective effects and has been used safely in super-old patients. Herein, we demonstrate successful anaesthetic management with peripheral nerve block under dexmedetomidine sedation for open reduction and internal fixation of a femoral neck fracture in a 97-yearold patient.

\section{BACKGROUND}

Hip fracture is a common injury and has been associated with increased major morbidity and mortality. ${ }^{1}$ In Japan, people aged over 65 years are classified into three groups as follows: age, 65-74 years as preold, $>75$ years as old and $>90$ years as super-old individuals. ${ }^{2}$ The number of patients, the old and super-old patients in particular, with hip fractures has drastically increased. ${ }^{3}$ Available anaesthetic management methods for hip fracture surgery in the elderly include general anaesthesia (GA) and regional anaesthesia (RA), including peripheral nerve block (PNB) and neuraxial anaesthesia (NA). NA includes spinal anaesthesia (SA) and epidural anaesthesia. GA and NA are often avoided in the elderly population for various reasons. Herein, we report successful anaesthetic management using femoral nerve block (FNB) and lateral femoral cutaneous nerve block (LFCNB) under dexmedetomidine (DEX) sedation for open reduction and internal fixation (ORIF) of a femoral neck fracture in a 97-year-old patient. Written informed consent was obtained from the patient's family for the publication of this report.

\section{CASE PRESENTATION}

A 97-year-old woman (body mass index (BMI), $14.8 \mathrm{~kg} / \mathrm{m}^{2}$; weight, $31.6 \mathrm{~kg}$ (measured later); height, $146 \mathrm{~cm}$ ) visited a local hospital with the chief complaint of right hip pain with an unknown history of present illness. After detailed physical and radiographic examinations, she was diagnosed with Garden type II of an intracapsular fracture of the right femoral neck (figure 1). She was referred to our hospital for further surgical treatment. She had a history of severe mitral regurgitation, mild dementia and chronic constipation. Her current pharmacotherapy includes three constipation medications and verapamil. Unfortunately, further internal medicine information was unavailable. ECG, performed at our emergency department, showed sinus rhythm.

The orthopaedic surgeons decided on a less invasive ORIF using cannulated cancellous screws (CCS) because of the minimal displacement of the fracture and advanced age of the patient.

We selected FNB and LFCNB under DEX sedation as the anaesthesia method because the planned ORIF required only a small incision. Additionally, to prevent intraoperative or postoperative complications, including hypotension, postoperative delirium (PD) and respiratory failure, and due to suspicion of fused vertebrae for vertebral fracture, GA and NA were avoided.

During the operation, the patient's blood pressure was monitored non-invasively, along with electrocardiography, pulse oximetry and continual skin temperature monitoring. To assess respiratory depression associated with sedation, nasal capnography-handmade with a suction catheter-was used to monitor end-tidal carbon dioxide and respiratory rate. Sedation level was assessed using the Observer's Assessment of Alertness/Sedation (OAA/S) scale. Her weight, which was not known, was estimated to be $40 \mathrm{~kg}$ based on her small frame, and we administered anaesthesia accordingly.

First, we performed a continuous infusion of DEX intravenously, at a high rate of $80 \mu \mathrm{g} / \mathrm{h}$ for 5 min, for sedation and administered $50 \mu \mathrm{g}$ fentanyl to induce analgesia simultaneously. Thereafter, the DEX dosage was decreased to $28 \mu \mathrm{g} / \mathrm{h}$ at a lower rate. Because $\mathrm{SpO}_{2}$ was decreased to $90 \%$ for sedation, we initiated oxygen administration via a face mask at $3 \mathrm{~L} / \mathrm{min}$; however, the sedation level was maintained at 3. PNB was performed using a linear ultrasound probe (HFL50, SonoSite, Bothell, Washington, USA) and a 5 -cm, 22-gauge needle (Stimuplex Ultra.360, B-Braun, Tochigi, Japan). The femoral nerve was located using a peripheral nerve stimulator plus an ultrasonic echo device. A $16-\mathrm{mL}$ dose of ropivacaine $(0.375 \%)$ was injected around the femoral nerve, and LFCNB was achieved with a 4-mL dose of ropivacaine $(0.375 \%)$. After including adequate local anaesthesia, surgery was initiated. 


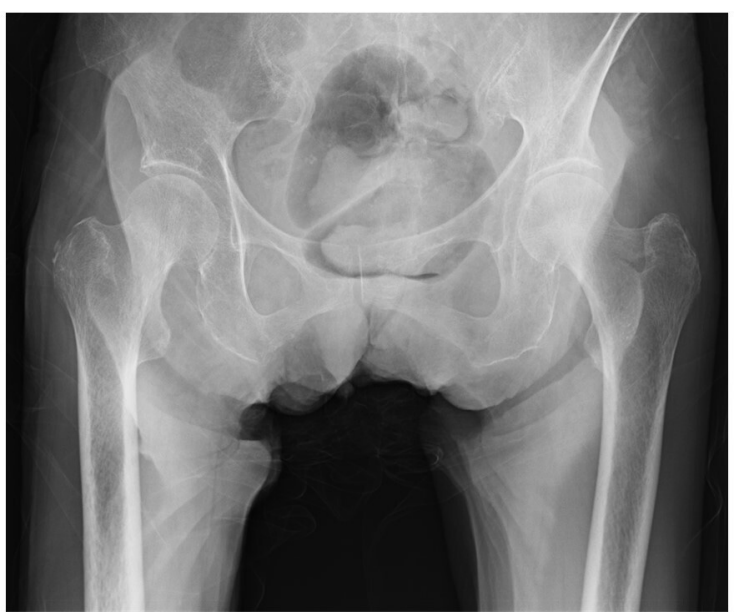

Figure 1 Initial plain radiograph of fracture; Garden type II of intracapsular fracture of the right femoral neck.

At the beginning of the surgery, the surgeons infiltrated $10 \mathrm{~mL}$ of $0.5 \%$ xylocaine with epinephrine into the skin incision for haemostasis. The patient showed signs of distress during the insertion of CCS into the femoral head (figure 2), following which an additional $50 \mu \mathrm{g}$ fentanyl was administered. For postoperative analgesia, we administered $600 \mathrm{mg}$ acetaminophen at the end of the surgery. The duration of the surgery was $9 \mathrm{~min}$ and that of anaesthesia was $42 \mathrm{~min}$. No vasopressor was required as our patient's intraoperative haemodynamic state remained stable (figure 3). No manual ventilatory assistance was required either because our patient's sedation level was 3-4 at mild-tomoderate levels, and her respiratory condition remained stable during surgery.

\section{OUTCOME AND FOLLOW-UP}

After surgery, the patient was transferred to the general ward and did not require any analgesics for at least 12 hours. The next day, rehabilitation was initiated and training for standing was possible. Eventually, she was transferred to a rehabilitation hospital on postoperative day 15 .

\section{DISCUSSION}

Hip fracture incidence rates increase exponentially with age. In Japan, from 2009 to 2014, this trend was prominently seen in

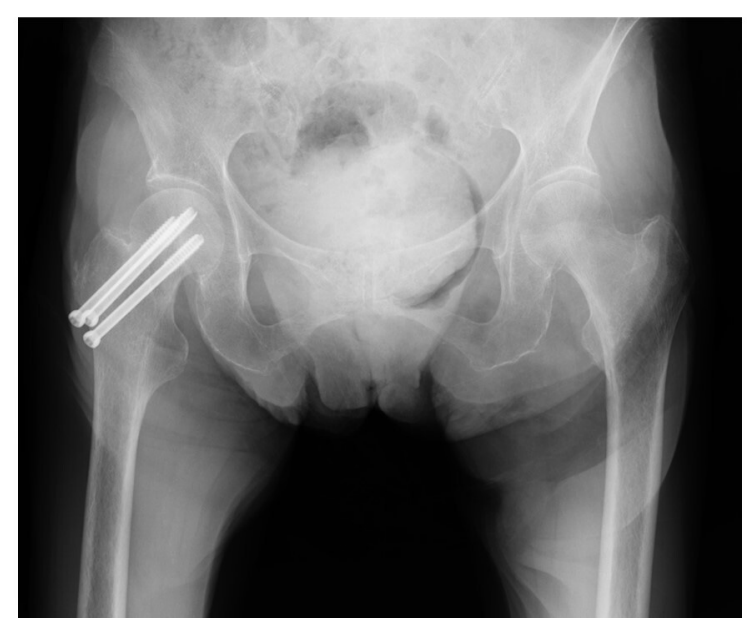

Figure 2 Plain radiograph after surgery showing internal fixation with three cannulated cancellous screws.

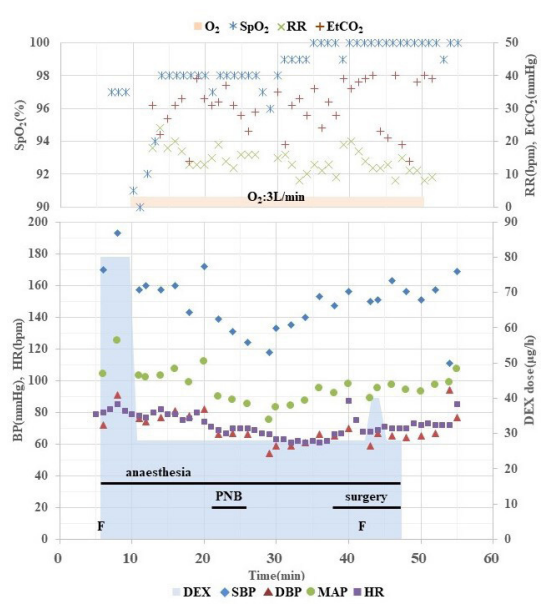

Figure 3 Perioperative time course. $\mathrm{BP}$, blood pressure; bpm, beats per minute; DBP, diastolic blood pressure; $\mathrm{DEX}$, dexmedetomidine; $\mathrm{EtCO}_{2}$, end-tidal carbon dioxide; $F$, injection of $50 \mu \mathrm{g}$ of fentanyl; $H R$, heart rate; $M A P$, mean arterial pressure; $P N B$, peripheral nerve block; RR, respiratory rate; $\mathrm{SBP}$, systolic blood pressure; $\mathrm{SpO}_{2}$, percutaneous oxygen saturation.

the 90-94 year age group in women and the 85-89 year age group in men. ${ }^{3}$ Therefore, hip fractures in super-old patients are expected to increase in the future. However, whether anaesthesia for hip fracture surgery in the elderly is best performed under GA or RA, including PNB or NA, remains debatable. The case of a 72-year-old patient who underwent ORIF with PNB has been reported ${ }^{4}$; however, to the best of our knowledge, there is no report of anaesthetic management in a 97-year-old patient. In this case, PNB under DEX sedation for ORIF was selected in a super-old patient.

The first reason to avoid GA and NA is hypotension. Intraoperative hypotension occurs commonly during hip fracture surgery, especially in elderly patients with a higher number of comorbidities. ${ }^{5}$ Internationally, the 30 -day mortality rate after hip fracture surgery is $6 \%-8 \%$; intraoperative hypotension is associated with increased 30-day mortality. ${ }^{1}$ Although GA or SA is usually selected for hip fracture ORIF, the incidence of intraoperative absolute hypotension (lowest systolic blood pressure $<90 \mathrm{~mm} \mathrm{Hg}$ ) is high in both GA and SA (49.2\% and 28.2\%, respectively). ${ }^{5}$ In recent years, PNB has proven to be effective in various orthopaedic procedures. Intraoperative blood pressure is higher during $\mathrm{PNB}$ than that during $\mathrm{GA}^{6}$ or $\mathrm{SA},{ }^{78}$ and $\mathrm{PNB}$ provides a more stable haemodynamic state. Owing to a history of severe mitral regurgitation and the potential for hypovolaemia, our patient's intraoperative haemodynamics were closely monitored. In fact, we believe that the patient's haemodynamics remained stable during the surgery because we selected PNB for anaesthetic management.

Additionally, intraoperative hypotension is associated with PD. ${ }^{9}$ PD occurs in $12 \%-51 \%$ of elderly patients following orthopaedic surgical treatment. ${ }^{10} \mathrm{PD}$ is associated with adverse clinical outcomes, such as high mortality rates, extended hospitalisation or further cognitive decline. ${ }^{910}$ Risk factors for PD include those that are patient-related and those that are adjusted in-hospital; thus, they are potentially prevented. ${ }^{9}$ Examples of the former include advanced age, low BMI, preoperative cognitive decline, polypharmacy (over three medications) and a high American Society of Anaesthesiologists (ASA) score. In contrast, the risk factors for the latter include intraoperative blood pressure (mean arterial pressure) control, blood transfusion and postoperative 
pain management. Our patient had a BMI of $14.8 \mathrm{~kg} / \mathrm{m}^{2}$ and an ASA score of 3. In short, avoiding intraoperative hypotension was important to ensure a good prognosis because our patient had an advanced age, low BMI, preoperative cognitive decline, polypharmacy and a high ASA score. Fortunately, our patient was transferred to a rehabilitation hospital without any problems.

We avoided GA and NA for several other reasons. We aimed to prevent the risk of postoperative respiratory failure, which occurs more significantly in the setting of GA. ${ }^{11}$ As the patient was 97 years old, poor outcomes were likely in case of respiratory failure after surgery. Moreover, as compared with SA, patients who underwent hip fracture surgery with GA have a higher risk of 30-day complications, such as the need for blood transfusion and risk of deep vein thrombosis. ${ }^{12}$ In contrast, we also wanted to avoid NA as it can be difficult to achieve because of the bent or fused spine of an elderly patient. Postoperatively, our patient was found to have a history of compression fracture of the third lumbar vertebra. Furthermore, as our patient had a history of mild dementia and experienced severe pain on movement, we judged that it would have been difficult for her to maintain the lateral position during NA. Lastly, had our elderly patient been on antithrombotic drugs for any indication, NA may also have been contraindicated. ${ }^{13}$

Intraoperative sedation is an important component of RA techniques and surgical procedures. We selected DEX as a supplement of the PNB and surgery because DEX is a selective $\alpha 2$ adrenergic receptor agonist with a large number of advantages, including fast-onset sedation with minimal respiratory depression, mild analgesic properties and the ability to improve postoperative recognition. ${ }^{14}$ In our patient, we assessed the level of sedation using the OAA/S score, a subjective assessment carried out intermittently depending on the patient's response to either verbal or physical stimuli. ${ }^{15}$ We believe that the combination of fentanyl bolus was a contributing factor for the decrease in oxygen saturation after the initiation of DEX. Since then, the patient had mild-to-moderate sedation levels and did not require manual ventilatory assistance. Despite the combination of PNB and a continuous infusion of DEX, the patient showed signs of distress while inserting CCS into the femoral head. This could be because the short time between the PNB and the initiation of

\section{Patient's perspective}

This was by far the best possible result to finish the surgery avoiding general anaesthesia and neuraxial anaesthesia. Thank you very much.

Learning points

- Hip fracture is a common injury and a growing healthcare challenge in an ageing society.

- Available methods for anaesthetic management for hip fracture surgery include general anaesthesia, neuraxial anaesthesia and peripheral nerve block.

- Peripheral nerve block appears to be an effective method to anesthetise super-old patients and may be used to replace general and neuraxial anaesthesia.

- As seen in our case, anaesthetic management using peripheral nerve block with dexmedetomidine sedation could contribute to the safety of hip fracture surgery in super-old patients. surgery may have resulted in inadequate analgesia to the femoral head. However, PNB is considered to have been effective, as the patient did not require any analgesics for at least 12 hours after surgery. Moreover, DEX exhibits neuroprotective effects and decreases the incidence of $\mathrm{PD},{ }^{16}$ leading to shorter hospital stays. ${ }^{1718}$ Furthermore, in elderly patients, intraoperative DEX use can remarkably improve the first night sleep quality after surgery, resulting in PD prevention. ${ }^{19}$ DEX has been used safely not only in our patient but also in another super-old patient. ${ }^{20}$ Briefly, DEX can be a useful anaesthetic adjuvant for a wide range of clinical applications due to its safety and effectiveness.

In summary, we achieved successful anaesthetic management with PNB and DEX in a 97-year-old patient for femoral neck fracture fixation. Because the incidence of hip fractures is expected to increase in the future, we believe that PNB is an effective method to anaesthetise super-old patients instead of GA or NA. Additionally, DEX has many advantages, including good sedation, analgesia and neuroprotective effects with minimal respiratory depression. In this case, our results suggest that anaesthesia using PNB under DEX sedation can contribute to the safety and effectiveness of hip fracture surgery in super-old patients.

Acknowledgements The authors would like to thank Dr Jun Nakanishi (Department of Orthopedics, Seirei Hamamatsu General Hospital) for useful discussions. They would like to thank Editage (www.editage.com) for the English language editing of this manuscript.

Contributors $\mathrm{Yl}$ was the major author of this manuscript, drafted the manuscript, contributed to the data collection, and obtained consent from the patient's daughter. YI participated in anaesthetic management. FO and SK supported anaesthetic management. FO, SK and YT supervised the manuscript drafting and provided critical feedback. All authors read and approved the final manuscript.

Funding The authors have not declared a specific grant for this research from any funding agency in the public, commercial or not-for-profit sectors.

Competing interests None declared.

Patient consent for publication Parental/guardian consent obtained.

Provenance and peer review Not commissioned; externally peer reviewed.

Open access This is an open access article distributed in accordance with the Creative Commons Attribution Non Commercial (CC BY-NC 4.0) license, which permits others to distribute, remix, adapt, build upon this work non-commercially, and license their derivative works on different terms, provided the original work is properly cited and the use is non-commercial. See: http://creativecommons.org/ licenses/by-nc/4.0/.

\section{ORCID iD}

Yoshiaki Ishida http://orcid.org/0000-0003-1589-9453

\section{REFERENCES}

1 Beecham G, Cusack R, Vencken S, et al. Hypotension during hip fracture surgery and postoperative morbidity. Ir J Med Sci 2020;189:1087-96.

2 Ouchi Y, Rakugi H, Arai H, et al. Redefining the elderly as aged 75 years and older: Proposal from the Joint Committee of Japan Gerontological Society and the Japan Geriatrics Society. Geriatr Gerontol Int 2017;17:1045-7.

3 Hagino $\mathrm{H}$, Endo N, Harada A, et al. Survey of hip fractures in Japan: recent trends in prevalence and treatment. J Orthop Sci 2017;22:909-14.

4 Yamazaki S, Omae T, Koh K, et al. Fixation of intracapsular fracture of the femoral neck using combined peripheral nerve blocks and transthoracic echocardiography in a patient with severe obstructive hypertrophic cardiomyopathy: a case report. JA Clin Rep 2019;5:64

5 Wood RJ, White SM. Anaesthesia for 1131 patients undergoing proximal femoral fracture repair: a retrospective, observational study of effects on blood pressure, fluid administration and perioperative anaemia. Anaesthesia 2011;66:1017-22.

6 Liu J, Yuan W, Wang X. Peripheral nerve blocks versus general anesthesia for total knee replacement in elderly patients on the postoperative quality of recovery. Clin Interv Aging 2014;9:341-50.

7 Lai HY, Foo LL, Lim SM, et al. The hemodynamic and pain impact of peripheral nerve block versus spinal anesthesia in diabetic patients undergoing diabetic foot surgery. Clin Auton Res 2020;30:53-60. 
8 Jeon $\mathrm{H}-\mathrm{J}$, Park Y-C, Lee JN, et al. Popliteal sciatic nerve block versus spinal anesthesia in hallux valgus surgery. Korean J Anesthesiol 2013;64:321-6.

9 Radinovic K, Markovic Denic L, Milan Z, et al. Impact of intraoperative blood pressure, blood pressure fluctuation, and pulse pressure on postoperative delirium in elderly patients with hip fracture: a prospective cohort study. Injury 2019;50:1558-64.

10 Inouye SK, Westendorp RGJ, Saczynski JS. Delirium in elderly people. Lancet 2014;383:911-22.

11 Van Waesberghe J, Stevanovic A, Rossaint R, et al. General vs. neuraxial anaesthesia in hip fracture patients: a systematic review and meta-analysis. BMC Anesthesiol 2017;17:87.

12 Fields AC, Dieterich JD, Buterbaugh K, et al. Short-Term complications in hip fracture surgery using spinal versus general anaesthesia. Injury 2015;46:719-23.

13 Li J, Oprea AD. Periprocedural management of patients on oral anticoagulation: focus on regional anesthesia [published online ahead of print, $2020 \mathrm{Ju}$ 3]. Pol Arch Intern Med 2020.

14 Zhao Y, He J, Yu N, et al. Mechanisms of dexmedetomidine in neuropathic pain. Front Neurosci 2020;14:330
15 Chernik DA, Gillings D, Laine H. Validity and reliability of the Observer's Assessment of Alertness/Sedation Scale: study with intravenous midazolam. J Clin Psychopharmacol 1990;10:244-51.

16 Zeng H, Li Z, He J, et al. Dexmedetomidine for the prevention of postoperative delirium in elderly patients undergoing noncardiac surgery: a meta-analysis of randomized controlled trials. PLoS One 2019;14:e0218088.

17 Lin C, Tu H, Jie Z. Effect of dexmedetomidine on delirium in elderly surgical patients: a meta-analysis of randomized controlled trials. Ann Pharmacother 2020;1060028020951954.

18 Pan H, Liu C, Ma X, et al. Perioperative dexmedetomidine reduces delirium in elderly patients after non-cardiac surgery: a systematic review and meta-analysis of randomized-controlled trials. Can J Anesth/J Can Anesth 2019;66:1489-500.

19 Cai J, Chen Y, Hao X, et al. Effect of intraoperative dexmedetomidine dose on postoperative first night sleep quality in elderly surgery patients: a retrospective study with propensity score-matched analysis. Front. Med. 2020;7:528.

20 Kunisawa T, Hanada S, Kurosawa A, et al. Dexmedetomidine was safely used for sedation during spinal anesthesia in a very elderly patient. J Anesth 2010;24:938-41.

Copyright 2021 BMJ Publishing Group. All rights reserved. For permission to reuse any of this content visit https://www.bmj.com/company/products-services/rights-and-licensing/permissions/

BMJ Case Report Fellows may re-use this article for personal use and teaching without any further permission.

Become a Fellow of BMJ Case Reports today and you can:

- Submit as many cases as you like

- Enjoy fast sympathetic peer review and rapid publication of accepted articles

- Access all the published articles

- Re-use any of the published material for personal use and teaching without further permission

Customer Service

If you have any further queries about your subscription, please contact our customer services team on +44 (0) 2071111105 or via email at support@bmj.com. Visit casereports.bmj.com for more articles like this and to become a Fellow 